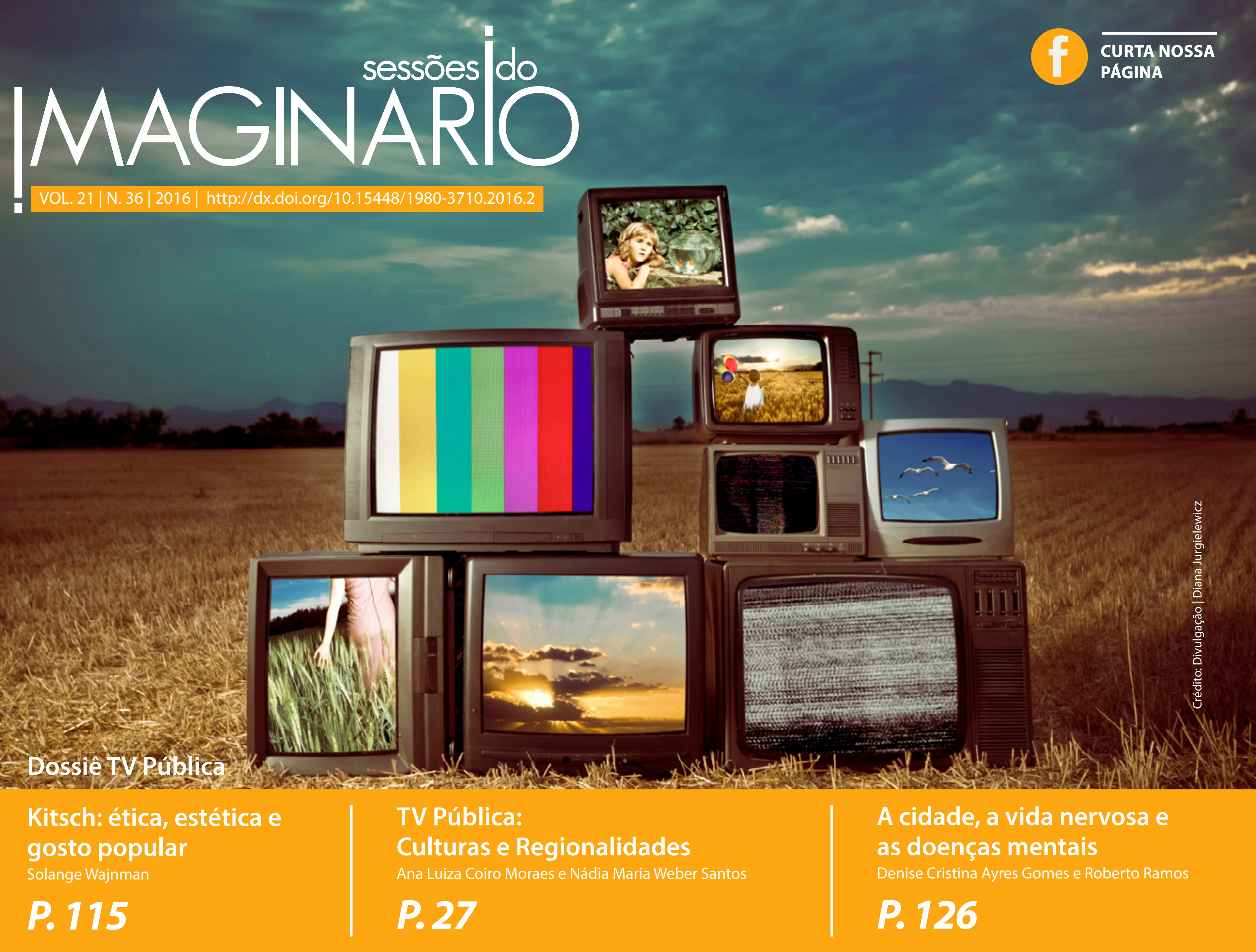




\section{As transmissões esportivas e o papel da TV pública no país: uma análise a partir dos casos da TV Cultura e da TV Brasil}

\section{Sports broadcasts and the role}

of public TV in the country: an analysis from the cases of TV Cultura and TV Brasil

\section{Ary José Rocco Jr. ' J}

Priscila Eugenia Trevisan Cestari $^{2}[$

\section{DOSSIÊ}

\section{Resumo}

Mais de seis décadas após o surgimento da TV no Brasil, o futebol segue como a modalidade esportiva que mais conta com tempo de exposição na TV, seja ela aberta ou fechada. Os principais campeonatos de futebol são transmitidos por empresas privadas, que compram os direitos de transmissão em troca de retorno financeiro e de audiência. Enquanto isso, a TV pública surge como alternativa às emissoras comerciais para a transmissão de eventos esportivos que não têm espaço na mídia comercial. Esse artigo tem como objetivo descrever e analisar as experiências de emissoras de caráter público como a TV Cultura-SP e a TV Brasil a partir da inclusão de programas e transmissões esportivas na grade de programação.

\section{Palavras-chave}

Esporte; TV pública;

TV Cultura; TV Brasil.

\section{Abstract}

Six decades later the first broadcasting television station appears in Brazil, football is the most showed sport on TV, either free or payed television channels. Most important football championships are showed by private companies that use the broadcast rights for making money and improve the audience. In these circumstances, the Public network became an alternative for commercial broadcaster's stations because it shows sport events that don't have place in the national networks. This article is going to describe and analyze the experiences of public service broadcasters such as TV Cultura-SP and TV Brazil, by the use of sports shows and sporting broadcasts in the television guide.

\section{Keywords}

Sport; public television;

TV Cultura; TV Brasil. 


\section{Introdução}

Mais de seis décadas após o surgimento da televisão no Brasil, o futebol segue como a modalidade esportiva que mais conta com tempo de exposição na TV, seja ela aberta ou fechada. De acordo com pesquisa IBOPE Repucom Sponsorlink Brasil (2014), o esporte na TV cresceu 53\% de 2007 a 2013, atingindo em sete anos 286,8 mil horas. Esses números incluem o tempo da transmissão de jogos, eventos, documentários e programas jornalísticos de todas as modalidades esportivas, sem incluir a Copa do Mundo (IBOPE, 2014).

O futebol é responsável pelo retorno financeiro às emissoras que detém os direitos de transmissão da cobertura esportiva. A exibição de jogos pela TV pode ser considerada uma vitrine para equipes que desejam visibilidade na mídia. Por outro lado, as emissoras se utilizam das transmissões esportivas para atrair consumidores de esporte (telespectadores e torcedores) e anunciantes interessados no produto futebol (Crisafulli e Dos Anjos, 2015).

No Brasil, os principais campeonatos de futebol são transmitidos por empresas privadas, que compram os direitos de transmissão em troca de retorno financeiro e de audiência (Savenhago, 2011). Em televisão aberta (canais de televisão gratuitos), os campeonatos nacionais de futebol são transmitidos pela TV Globo (Campeonato Brasileiro Série A), Rede TV! (Campeonato Brasileiro Série B) e TV Brasil (Campeonato Brasileiro Série B, Série C e Série D).

Enquanto as equipes que disputam a primeira e segunda divisão do Campeonato Brasileiro (Séries A e B) recebem pelos direitos de transmissão, na terceira e quarta divisões o repasse dos direitos não é feito dire- tamente aos clubes. As emissoras que transmitem as partidas - no caso a TV Brasil (em sinal aberto) e o canal Esporte Interativo (canal sintonizado em UHF em TV aberta, por parabólica e pela TV por assinatura) - pagam diretamente à Confederação Brasileira de Futebo (CBF) os valores desses direitos, e a entidade repassa aos clubes os valores como pagamento de ajuda de custo.

Ao oferecer o futebol como produto esportivo aos telespectadores, questiona-se se a TV pública cumpre a sua missão, que é a de difundir conteúdos que contribuem para a formação crítica das pessoas, o que poderia ser um diferencial da cobertura realizada pelas emissoras comerciais. O futebol é uma maneira de a TV pública se tornar conhecida do telespectador brasileiro, porém, Lopes (2015) justifica a existência de uma TV pública com a proposta de mostrar a diversidade do país e fortalecer a cidadania, que deve ser construída de forma consistente.

Por meio de levantamento bibliográfico e de fontes secundárias, esse artigo propõe contextualizar o surgimento da TV pública no país, relacionando as experiências das TVs Cultura-SP e TV Brasil com o esporte, tanto na produção de programas como nas transmissões de eventos. Justifica-se a escolha destas duas emissoras de TV pública para esse estudo pois, em momentos dis tintos e de forma diversa, investiram no esporte como parte importante de sua grade de programação. Espera-se observar na análise desta evolução histórica se as TVs públicas cumprem, de fato, seu papel ao incluir a transmissão de campeonatos de futebol em sua programação. Na medida em que a discussão sobre a Comunicação Pública é um processo ainda em construção (Brandão, 2006), espera-se contribuir para o diálogo especificamente com o esporte, a mídia e as transmissões esportivas em emissoras públicas de televisão.

\section{A TV pública no Brasil: breve histórico}

No mundo, as televisões púbicas surgiram antes mesmo das emissoras comerciais. A BBC na Inglaterra, a TVE na Espanha, a France Televison, a RTP de Portugal, a ARD e a ZDF, alemãs, por exemplo, nasceram como televisões estatais, controladas pelos governos nacionais. Na América do Norte, outras experiências da radiodifusão pública também se destacam: a Public Broadcasting Service (PBS), nos Estados Unidos, e a Canadian Broadcasting Corporation (CBC), no Canadá (Valente, 2009; Moyses et al., 2009).

Ao contrário do que ocorreu na Europa, as iniciativas para implantar serviços públicos de radiodifusão no Brasil estavam subordinadas ao modelo comercial, atuando de forma complementar (Leal Filho, 2007). Pela legislação brasileira, o controle da radiodifusão é público e cabe ao Poder Executivo conceder e renovar concessões de acordo com o artigo 223 da Constituição Federal de 1988, além de permitir e autorizar os serviços de radiodifusão sonora e de sons e imagens, aprovar as transferências diretas e indiretas das outorgas, observado o princípio da complementaridade dos sistemas privado, público e estatal.

Apesar deste artigo estabelecer três sistemas, o público e o estatal precisavam ser diferenciados por algum critério e atuar de forma complementar. O sistema estatal tem características não-comerciais, com programação voltada à divulgação e transparência dos atos institucionais e à prestação de contas da administração pública em suas três esferas de poder: o Executivo, o Legislativo e o Judiciário (Valente, 2009). Enquanto que o sistema público, não-estatal, seria aquele que opera também sem intenção de lucro, mas as diretrizes de 
gestão da programação e a fiscalização devem ser atribuição de órgão colegiado deliberativo, representativo da sociedade, no qual o Estado ou o governo não devem ter maioria (Carta de Brasília, 2007).

A partir do $1^{\circ}$ Fórum Nacional de TVs Públicas, em que diversos setores da sociedade civil participaram das reflexões sobre a comunicação, foram traçadas diretrizes para a introdução da televisão pública no país (Leal Filho, 2007; Bolaño e Brittos, 2011). Essa iniciativa resultou na Carta de Brasília, que se constitui em um conjunto de reivindicações para o sistema público de comunicação e "que se tornou marco de referência para a discussão da televisão pública no Brasil" (Otondo, 2012, p.140). Os autores do documento afirmam que "a TV Pública promove a formação crítica do indivíduo para o exercício da cidadania e da democracia" (Carta de Brasília, 2007).

Alguns meses depois, a proposta foi colocada em prática e deu origem a Empresa Brasil de Comunicação (EBC) a partir da edição da Medida Provisória 398, em 25 de outubro de 2007, posteriormente convertida pelo Congresso na Lei 11.652/20083. Ao herdar os canais de rádio e TV da estatal Radiobrás e da TVE do Rio de Janeiro, a EBC ficou encarregada de unificar e gerir as emissoras federais já existentes, instituindo o Sistema Público de Comunicação (Moyses et al., 2009).

As emissoras públicas foram criadas para proteger a vitalidade dos debates e das manifestações culturais que a sociedade deve pautar, produzir e preparar em seu domínio civil próprio, independentemente do Estado e também do mercado (Bucci, 2010). Mas, como uma das principais fontes de recursos dessas empresas provém do orçamento, seja da União ou dos Estados, a relação com o governo que delega o serviço e ao mesmo tempo deve dar os recursos e a liberdade necessária para cumprir a missão e funções "é um ponto nevrálgico do cotidiano da TV Pública" (Otondo, 2012, p.50).

Eugenio Bucci, que foi presidente da Radiobrás entre 2003 e 2007, defende que o caráter verdadeiramente público de uma emissora de radiodifusão é a gestão independente. Para ele, “o negócio da televisão pública não é entretenimento e, indo mais longe, não é sequer televisão: é cultura, é informação, é liberdade" (Bucci, 2010, p. 17). Desse modo, uma TV pública deveria ser uma opção ao modelo de televisão comercial ao oferecer uma programação de qualidade sem se preocupar com a audiência que geralmente é estabelecida - e cobrada - pelo mercado.

Há pelo menos três princípios que se inter-relacionam em uma televisão pública dirigida à construção da cidadania: estabelecer uma programação de qualidade; ocupar os espaços vagos deixados pela televisão comercial, refletindo na questão de gênero com intenção de educar ou conscientizar; e considerar a diversidade cultural, tolerância e abertura a outros assuntos culturais, respeitando e abordando diferenças étnicas, de classes sociais, gênero, idade, de maneira plural (Mazzioti, 2002).

Na televisão, o esporte é uma das poucas práticas que tem amplo espaço, com vários programas especializados. Em razão disso, a escolha de uma transmissão esportiva em emissoras públicas deveria ter como objetivo conquistar espaços diferenciados e difundir conteúdos que contribuam para a formação crítica dos indivíduos, mas sem se preocupar com a audiência. A seguir, serão apresentadas experiências em TV pública relacionadas ao esporte com a TV Cultura, de São Paulo, e a TV Brasil.
A TV pública e o esporte: TV Cultura-SP e TV Brasil

Desde o início da década de 1970, o Brasil conta com um sistema público estatal de televisão educativa atingindo praticamente todo o território nacional, constituído por emissoras ligadas, na sua maioria, aos governos estaduais - com algumas poucas ligadas às universidades federais (Bolaños e Brittos, 2008). A primeira televisão pública a transmitir programação foi a TV Universitária, canal 11 de Recife, pertencente à Universidade Federal de Pernambuco, inaugurada em novembro de 1968 (Lima, 2008; Otondo, 2012).

Para esse estudo, foram escolhidas duas emissoras públicas que, em diferentes momentos de sua existência, optaram por incluir o esporte em sua grade de programação: a TV Cultura, de São Paulo, e a TV Brasil, com sede no Distrito Federal, e com emissoras de TV em outros três estados: Maranhão, Rio de Janeiro e São Paulo.

\section{TV Cultura-SP}

Controlada pela Fundação Padre Anchieta (FPA), uma entidade pública e não-estatal, a TV Cultura de São Paulo costuma ser apontada como referência de emissora pública no país. Criada em meio ao governo militar, "na sua concepção original não era, portanto, nem uma televisão de governo, nem uma televisão do Estado, mas uma televisão educativa e cultural, destinada à educação de massa e à distância" (Otondo, 2012, p. 238). Iniciou as atividades no dia 15 de junho de 1969, quando fez a primeira transmissão a partir de uma festa no Ginásio do Ibirapuera, em São Paulo (Lima, 2008).

A Fundação Padre Anchieta tem como missão "contribuir para a formação crítica do homem para o pleno 
exercício da cidadania e a defesa e o aprimoramento integral da pessoa humana". Atualmente, mantém a TV Cultura, rádios Cultura FM e Cultura Brasil, canal digital MultiCultura e o portal CMAIS. Tem parceria na operação do canal digital TV Univesp e distribui conteúdo infantil pelo canal "TV Ra Tim Bum!" (canal de TV por assinatura). A Fundação também é responsável pela distribuição de conteúdos informativos, educacionais e culturais, por meio da produção, geração e incentivo à realização de produtos para televisão, rádio e web.

O esporte faz parte da grade de programação da TV Cultura desde 1969. O tema principal era o futebol, porque o surgimento da emissora coincidiu com o ano de preparação da seleção brasileira para o mundial disputado no México, em 1970. Os primeiros programas exibidos na emissora paulista foram História do Esporte e É Hora de Esportes, o primeiro noticiário esportivo exibido no horário do almoço (Lima, 2008).

Em 1972, a TV Cultura estreou o Esportevisão, a primeira revista eletrônica da TV brasileira, exibida aos sábados. A TV Cultura também foi responsável pela transmissão de competições de atletismo (jogos abertos do interior e campeonato brasileiro), natação, vôlei, basquete e outros esportes olímpicos (Rocha, 2006).

Anos mais tarde, Grandes Momentos do Esporte, exibido de 1984 a 2012, destacou-se por resgatar acontecimentos esportivos. Apesar de o futebol ser o carro-chefe, reportagens especiais com edição e abordagem diferenciadas fizeram com que o programa alcançasse destaque no jornalismo esportivo (Lima, 2008; Rocha, 2006). O programa Vitória, que estreou em 1986 e se apresentava como um programa jovem e de formato inovador, tinha foco em esportes radicais pouco abordados pela mídia: utilizava a estética e a musicalidade dos videoclipes na edição de suas matérias, revolucionando a forma de exibir esportes na TV brasileira (Lima, 2008).

Em 1993, o Cartão Verde entrou na grade de programação da TV Cultura. Idealizado pelo jornalista Michel Laurence, o programa foi exibido aos domingos até 2002, com apresentação de Armando Nogueira, Flávio Prado, José Trajano e Juca Kfouri. Em formato de mesa-redonda o programa debatia os esportes em geral, mas com destaque para o futebol. Atualmente é o único programa de esportes na grade de programação e é comandado pelos jornalistas Vladir Lemos, Vitor Birner, Celso Unzelte e pelo ex-jogador Roberto Rivelino, que recebem um convidado diferente a cada edição (Portal CMais; Tosta e Coutinho, 2013).

Em relação às transmissões esportivas, a ampliação do sinal de transmissão para o interior paulista, em 1981, levou a TV Cultura a realizar caravanas para a realização das partidas exibidas pela emissora. A TV Cultura contava com um ônibus verde que realizava as transmissões esportivas que foi apelidado de "gafanhoto", "um instrumento essencial e moderníssimo (levando em conta a esfera das televisões educativas) para a tecnologia oferecida aos telespectadores" (Tosta e Coutinho, 2013, p. 32).

As partidas do mundial de futebol da Alemanha (1974) e da Argentina (1978) foram transmitidas pela TV Cultura com narração de Luiz Noriega e de Walter Abrahão. Na copa de 1982, no México, a TV Cultura exibiu os jogos em parceria com a Rede Globo (Tosta e Coutinho, 2013). Entre os anos de 1991 a 1994, a emissora paulista abriu espaço ao futebol internacional: transmitiu as partidas do Campeonato Alemão, aos domingos, até 1993; o futebol japonês (de 1993 a 1994), a chamada de J-League (Campeonato Japonês). E em 1998, a TV Cultura, em parceria com a UEFA (União Europeia das Associações de Futebol) exibiu a Copa da Europa (Do Valle, 2015).
A TV Cultura retomou as transmissões esportivas anos depois com a Copa das Confederações, a Copa São Paulo de Futebol Júnior e a Copa Cultura de Juniores, organizada pela própria emissora em 2005. No ano seguinte, o destaque foi a transmissão do Campeonato Português, temporada 2006/2007, com exclusividade em TV aberta.

Para a direção da emissora essa era uma forma de "dar oportunidade para que o público veja um grande campeonato, com diversas equipes e uma quantidade enorme de jogadores brasileiros", em um trabalho de aproximação entre os dois países (Portal UOL, 2006). Quatro anos mais tarde, o canal da Fundação Padre Anchieta sublicenciou do Esporte Interativo os direitos de transmissão do Campeonato Italiano para a temporada 2009/2010. Os jogos do torneio europeu eram exibidos aos domingos na TV Cultura (Bertozzi, 2009).

Um exemplo de que o conteúdo esportivo da TV pública se relaciona ao contexto do esporte e como ele é praticado, foi a criação da faixa Cultura Esporte Clube, em 2011, quando a TV Cultura transmitiu o $1^{\circ}$ Campeonato Estadual de Seleções de Ligas Municipais. A competição, organizada pela Federação Paulista de Futebol em parceria com a Secretaria Estadual de Esporte, Lazer e Juventude de São Paulo, reuniu mais de mil atletas de 36 clubes amadores das principais cidades do interior de São Paulo em jogos disputados aos domingos, entre os meses de maio e outubro (Portal CMais, 2011).

Além da experiência esportiva da TV Cultura-SP, outra emissora pública que adotou o esporte em sua grade de programação foi a TV Brasil. A emissora da Empresa Brasil de Comunicação (EBC) existe desde 2007, mas absorveu da antiga TV Educativa, do Rio de Janeiro, os antigos programas esportivos. $\mathrm{E}$, desde 2010, incluiu em 
sua programação a transmissão de partidas de campeonatos nacionais de futebol.

\section{TV Brasil}

Em relação à abordagem do esporte na TV Brasil, o Manual de Jornalismo da EBC considera que os fatos do universo esportivo devem ser pautados pelo jornalismo e estão distribuídos em temas ligados às competições, comportamento, economia, entre outros, e o esporte como fator de promoção da saúde, integração, educação, inclusão.

Os documentos que regulamentam a linha editorial para o esporte na TV, e demais veículos da EBC (rádio e agência de notícias), são os Planos de Trabalho e o Manual de Jornalismo. Os documentos trazem valores como priorização do esporte na cobertura jornalística, complementariedade dos sistemas de comunicação, integração de plataformas, inclusão social e cultural, pluralidade de temas e modalidades, inovação, abordagem diferenciada e diferenciação entre o esporte de alto desempenho e o amador (EBC, 2015).

Entre as premissas da EBC para a cobertura esportiva, e que se encontram no Manual de Jornalismo, de 2013, duas são destacadas neste estudo: a atenção para os mais diferenciados esportes e modalidades, e a proposta de ações que despertem interesse pela cidadania. Embora o futebol seja o esporte que mais envolva e mobilize a população, "o esporte não se resume ao futebol profissional" e, além disso, a cobertura dos eventos deve propiciar ao jornalismo da EBC "incluir informações que possam despertar o interesse do torcedor por ações de cidadania" (Manual de Jornalismo, p.60).

Por ter origem na antiga TVE do Rio de Janeiro, desde o início a TV Brasil mantém dois programas de esporte na grade da programação: No Mundo da Bola (antigo EsporTVisão) e o Stadium. O EsporTVisão se despediu da tela da TV Brasil no dia 9 de julho de 2013: em formato de mesa-redonda, o programa teve 546 edições, sendo a primeira no ano de 2002.

O nome da nova mesa redonda na TV foi inspirado no programa homônimo da Rádio Nacional do Rio de Janeiro, e que nasceu nos anos de 1930 sob o comando do locutor esportivo Antônio Cordeiro. No Mundo da Bola estreou na TV Brasil em 16 de junho de 2013, sob o comando dos jornalistas Sergio Du Bocage, Alberto Léo e Márcio Guedes e todos os domingos os principais acontecimentos do esporte no Brasil e no mundo estão em destaque.

Em formato de revista semanal, o Stadium existe há 39 anos. O programa tem como foco os esportes Olímpicos e Paraolímpicos e procura mostrar de um jeito diferente tudo que movimenta o mundo do esporte, além de abrir espaço para atletas que ainda não têm apoio, mas que representam grandes promessas de títulos para o Brasil. A primeira edição foi ao ar no dia 25 de fevereiro de 1978, apresentada pela jornalista Rosemary Araújo.

Em relação à transmissão de eventos esportivos, em 2010 a TV Brasil foi a primeira emissora pública em canal aberto a exibir jogos do Campeonato Brasileiro da Série C. O entendimento de se colocar futebol na grade de programação era o de oferecer um produto que poucos gestores tinham interesse em veicular. $O$ elemento principal estava ligado ao mandato da EBC, que é a regionalização, proposta reforçada no artigo $3^{\circ}$ da lei que criou a empresa, que é a de promover a cultura nacional, pois muitos times eram do Norte e Nordeste na Série C, estados que faziam parte da Rede Pública de Televisão (Brasil, 2008). Pela TV Brasil e pelas retransmissoras e parceiras foram exibidos 14 jogos (aos sábados, às 16h, e aos domingos, às 10h), entre as oito equipes que disputavam as quatro vagas de acesso à Série B do Campeonato Brasileiro.

Por motivos orçamentários e financeiros, entre 2011 e 2012, a TV Brasil não transmitiu a Série C. Após reunião com a CBF para negociar a compra dos direitos de transmissão do campeonato, a diretoria da empresa concluiu "que seria imprudente destinar ao referido evento esportivo, embora reconhecendo sua importância e relevância, recursos que poderiam comprometer outras atividades da empresa e do Sistema Público de Comunicação que gerencia" (EBC, 2011).

A TV Brasil transmitiu a $5^{\text {a }}$ edição dos Jogos Mundiais Militares, disputados entre 16 e 24 de julho de 2011, no Rio de Janeiro, com a participação de 6 mil atletas de 110 países, reunidos em 20 modalidades esportivas, sendo 15 delas olímpicas, como atletismo, natação, hipismo, basquete, futebol, vôlei, vela e boxe. O contrato assinado pela EBC com o Ministério da Defesa não teve custos, isto é, não houve pagamento pelo direito de transmissão do evento, que também foi adquirido por seis emissoras comerciais (Costa, 2010).

As transmissões dos jogos da Série $C$ retornaram em 2013, com a exibição de dois jogos por rodada, aos sábados e domingos às 19 horas, e participação dos clubes divididos em dois grupos com 10 times cada, representando todas as regiões do país. Um dos destaques nesta cobertura foi a liderança de audiência no Recife, pela TV Universitária de Pernambuco, no dia 3 de novembro, durante o jogo Santa Cruz (PE) x Betim (MG), quando a emissora registrou audiência acima da TV Globo, que exibia uma partida do campeonato da primeira divisão. Na época, o jornalista Daniel Castro, especializado em Televisão, fez um comparativo entre a audiência da Série A e da Série C: 
Emissora que raramente sai do traço, a TV Brasil experimentou a liderança da audiência no último domingo (3), no Recife, com a transmissão do jogo entre Santa Cruz e Betim, válido pelas semifinais da Série C do Campeonato Brasileiro. Durante a transmissão da partida que garantiu o time pernambucano na segunda divisão do futebol nacional, a emissora pública registrou média de 11,5 pontos de audiência e picos de 19,4. A Globo, que transmitia a Série A do Brasileirão, ficou em segundo lugar, com apenas 8,5 pontos (Castro, 2013).

O resultado, que ilustra a situação de um evento local (Santa Cruz para o Recife) contra um nacional (veiculado pela TV Globo), garantiu a liderança na audiência, representando mais de 200 mil domicílios sintonizados na transmissão da TV Brasil numa partida que teve mais de 60 mil torcedores no estádio do Arruda, em Recife (Santos, 2013). O caso ganhou repercussão e com o destaque e o sucesso conquistado no fator de audiência em 2013, o torneio ganhou visibilidade por parte das emissoras.

Para 2015, a emissora adotou como lema "O ano do esporte na TV Brasil", depois de ter sublicenciado eventos esportivos internacionais como a Copa do Mundo de Futebol Feminino (Canadá); os mundiais sub-20 (Nova Zelândia) e sub-17 (Chile), além do mundial de Futebol de Areia (Portugal). O valor do sublicenciamento foi de US\$ 250 mil, pagos à Rede Globo, que transmitiu os eventos apenas pelo canal por assinatura SporTV (EBC, 2015).

Nesse mesmo ano, a TV Brasil também transmitiu o Campeonato Brasileiro Feminino de Futebol (de setembro a dezembro) e algumas partidas das fases de quartas-de-final, semifinal e finais dos Campeonatos Brasilei- ros da Série B e Série D, segunda e quarta divisão do futebol, respectivamente. O último torneio transmitido em 2015 foi a Copa Placar de Seleções Sub-20, disputado por quatro seleções: São Paulo, Rio de Janeiro, Minas Gerais e Rio Grande do Sul.

No início de 2016, a TV Brasil realizou as transmissões da $47^{\circ}$ edição da Copa São Paulo de Futebol Junior principal competição de atletas sub-20 do país. De acordo com a Federação Paulista de Futebol (FPF), o torneio reuniu 112 times, divididos em 28 grupos. A emissora participou de um pool de transmissão com a exibição de 12 partidas ao vivo entre os dias 2 a 25 de janeiro.

Após a Copa Sub-20, a TV Brasil transmitiu 15 partidas do Campeonato Brasileiro de Futebol Feminino. Disputado por 20 equipes, na primeira fase, as equipes que representavam todas as regiões do país, foram divididas em quatro grupos de cinco times. A equipe do Flamengo, do Rio de Janeiro, sagrou-se campeã nacional de futebol feminino em 2016.

De acordo com o contrato de Licenciamento, Direito de sublicenciamento e captação de áudio em HD para a temporada 2015/2016, firmado entre a EBC e a Sport Promotion (empresa de marketing esportivo que negocia os direitos de transmissão entre a CBF e as emissoras de TV), a TV Brasil se comprometeu a transmitir 117 jogos ao vivo entre outubro/2015 e novembro/2016.

Especificamente neste contrato, os direitos de transmissão exclusivos da TV Brasil são os da Série C e do Futebol Feminino, e a emissora faz a escolha dos jogos que serão exibidos em sua grade de programação. Enquanto os direitos de transmissão das séries B e D não são exclusivos, ou seja, a emissora compartilha com outros canais (TV Globo, Rede TV! e SporTV) as exibições das partidas não têm influência na escolha do jogo que entra na grade de programação.
Os direitos de transmissão da temporada da Série C em 2015, com exibição mínima de 40 partidas entre abril e novembro, custaram para a EBC o valor de $\mathrm{R} \$$ 9.991.618,67. No mesmo ano, a emissora transmitiu com exclusividade em TV aberta oito jogos da Série D (semifinais e finais) e oito jogos do Campeonato Brasileiro de Futebol Feminino (semifinais e finais), com contrato de setembro a novembro no valor de $\mathrm{R} \$ 978.000,00$ (EBC, 2015).

Na temporada de 2016, os valores da Série C não foram detalhados no contrato que, por sua vez, contemplou em um mesmo pacote a aquisição dos direitos das Séries B, D e Campeonato Brasileiro de Futebol Feminino, no valor de $\mathrm{R} \$ 14.981 .346,75$. Nesse caso, uma cláusula do contrato chama a atenção: a equipe da Sport Promotion se comprometeu a realizar a geração de 20 jogos dos Campeonatos do futebol do Estado de São Paulo, sem qualquer custo à EBC, "ficando certo que essa geração adicional apenas ocorrerá na hipótese de aquisição dos direitos desses campeonatos pela contratante (EBC), junto à entidade detentora dos direitos".

Assim, a emissora buscou ampliar a audiência para o estado de São Paulo e transmitiu os campeonatos Paulista de Futebol Série A2 e A3, exibindo duas partidas por semana: uma aos sábados e outra aos domingos. Além do futebol, a emissora transmitiu as partidas das semifinais e das finais da Copa do Brasil de Vôlei Feminino e Masculino, em 2015 e 2016, com imagens que foram geradas por meio de parceria da TV Brasil com o canal SporTV.

Entre os dias 7 e 18 de setembro, a TV Brasil transmitiu os Jogos Paraolímpicos do Rio de Janeiro. No país, os direitos de transmissão eram da Globosat e foram sublicenciados para a TV Brasil, sendo que o valor do contrato foi de R\$495.868,00 (EBC, 2015). Com o slogan 
"O canal das Paraolimpíadas", a TV Brasil exibiu aproximadamente 10 horas diárias de programação dedicada exclusivamente ao evento - entre competições ao vivo e reportagens jornalísticas -, além da transmissão das cerimônias de abertura e de encerramento (EBC, 2016).

\section{Considerações finais}

A partir dos históricos das TVs Cultura-SP e TV Brasil, nota-se que houve uma certa atenção e esforço para que o esporte fizesse parte da grade de programação destas emissoras em momentos distintos. Por ser uma modalidade que mais conta com tempo de exposição na TV, o futebol ainda é o carro-chefe da programação e das transmissões esportivas, e de conteúdo jornalístico quando se fala em esporte na TV brasileira, seja ela aberta ou fechada, pública ou comercial. Com a passagem dos anos, o esporte permitiu que as emissoras ganhassem visibilidade e alguma audiência pelos campeonatos que transmitem.

A missão da TV Cultura destaca o "exercício da cidadania" enquanto que a da EBC/TV Brasil, propõe "criar e difundir conteúdos que contribuam para a formação crítica das pessoas". Ao transmitir campeonatos que, muitas vezes, não tem espaço em emissoras comerciais, as emissoras públicas oferecem uma programação complementar, além de mostrar a diversidade do país. Mas, o conteúdo realmente diferenciado que atinge diretamente o cumprimento da missão, ou mesmo, no caso da EBC, as premissas para a cobertura esportiva, (que são a atenção aos diferentes esportes e modalidades, e a proposta de ações para despertar o interesse pela cidadania), não foram identificados. Todas as emissoras têm o foco somente no futebol.
Se as emissoras públicas estão preocupadas com aumento e retorno da audiência, do espetáculo e da visibilidade, arriscam-se em seguir o caminho das emissoras que utilizam o esporte em troca de retorno comercia e financeiro. E, assim, desviam completamente daquilo que tem como missão proposta e não cumprem o papel para o qual foram criadas. Afinal, no momento em que o esporte é comercializado, os espectadores passam a ser em maior número do que os participantes e, de certa forma, são o público-alvo da mídia televisiva para se tornar mais consumidores do espetáculo e menos voltados para a construção da cidadania.

Por estarem submetidas à dependência do orçamento federal (TV Brasil) e estadual (TV Cultura), ou mudanças de governo, as emissoras públicas ainda correm o risco de não cumprirem seus contratos, caso as verbas destinadas para esses projetos sejam contingenciadas. Este é um "exemplo da dificuldade de a empresa fazer projetos a médio e longo prazos, que resultam na interrupção de certos programas ou gêneros mais populares entre a audiência" (Lopes, 2015, p.50).

Esse estudo sugere que as emissoras que fazem parte da TV pública experimentem ações externas às transmissões ou ao conteúdo jornalístico, isto é, aproveitem as competições esportivas para relacioná-las aos fatores que promovem a saúde, inclusão social, cultura, educação e lazer. Ao incluir na grade de programação modalidades que geralmente não fazem parte das transmissões das emissoras comerciais, a TV pública poderia ser uma alternativa que vai além do futebol e contribui para ampliar a cobertura e/ou transmissão de outros esportes com pouco ou quase nenhum espaço na mídia.

Como proposta para estudos futuros, os pesquisadores podem traçar um perfil do torcedor que acompanha os eventos esportivos das emissoras públicas, para que por meio do marketing, sejam realizadas ações que aproximem os telespectadores das ações dos meios de comunicação. Ao identificar o perfil deste indivíduo, as emissoras poderiam atrair visibilidade e audiência para seus próprios produtos, sem desviar o propósito para o qual foram criadas.

\section{Referências}

BERTOZZI, P. El faz parceria com Cultura pelo Italiano. Máquina do Esporte, 2009. Disponível em: <http:// maquinadoesporte.uol.com.br/artigo/ei-faz-parceriacom-cultura-pelo-italiano_9310.html>. Acesso em 10 fev 2016.

BOLAÑO, C. R.; BRITTOS, V. C. TV pública, políticas de comunicação e democratização: movimentos conjunturais e mudança estrutural. Revista Eptic, v. 10, n. 3, 2011.

BRANDÃO, E. Usos e significados do conceito Comunicação Pública. Intercom/2006. Disponível em: <http://intercom.org.br/papers/nacionais/2006/ resumos/R1037-1.pdf>. Acesso em 25 jan 2016.

BRASIL. Lei no 11.652/2008. Disponível em: <http:// www.planalto.gov.br/ccivil_03/_ato2007-2010/2008/lei/ I11652.htm>. Acesso em 25 set 2015.

BUCCl, E. É possível fazer televisão pública no Brasil? Novos Estudos-CEBRAP, n.88, p.05-18, 2010.

CARTA DE BRASÍLIA. Manifesto pela TV Pública independente e democrática. I Fórum Nacional de TVs públicas: Brasília, 2007. 
CASTRO, D. TV Brasil derrota Globo no Recife com Série C do Brasileirão. 04 nov 2013. Disponível em: <http://noticiasdatv.uol.com.br/noticia/audiencias/ tv-brasil-derrota-globo-no-recife-com-serie-c-dobrasileirao-1006>. Acesso em 25 nov 2014.

CRISAFULLI, F; DOS ANJOS, L. O critério da solidariedade na análise concorrencial do joint selling no mercado de transmissão televisiva do futebol brasileiro. Revista de Defesa da Concorrência, v. 3, n. 2, 2015.

DO VALLE, E. Como o futebol internacional era transmitido para o Brasil antes das TVs a Cabo. Portal Trivela, 2015. Disponível em: <http://trivela.

uol.com.br/como-o-futebol-internacional-eratransmitido-para-o-brasil-antes-das-tvs-a-cabo>. Acesso em: 10 fev 2016.

EBC. TV Brasil desiste da Série $C$ por razões orçamentárias. Portal EBC, 2011. Disponível em: <http:// www.ebc.com.br/sobre-a-ebc/sala-de-imprensa/2011/05/ tv-brasil-desiste-da-serie-c-por-razoes-orcamentarias>. Acesso em 25 jan 2016.

EBC. Cerimônia de encerramento dos Jogos Paralímpicos Rio 2016. Disponível em: <http://tvbrasil. ebc.com.br/paralimpiadas2016/episodio/cerimonia-deencerramento-dos-jogos-paralimpicos-rio-2016>. Acesso em 24 out 2016

EBC. Contratos de Conteúdo. Brasília, 2015. PORTAL UOL. TV Cultura vai transmitir Campeonato Disponível em: <http://www.ebc.com.br/institucional/ acessoainformacao/licitacoes-e-contratos/contratos-deconteudo>. Acesso em: 25 jan 2016.
IBOPE. Repucom Sponsorlink Brasil. Disponível em: <https://www.kantaribopemedia.com/um-pais-querespira-esportes>. Acesso em 25 jan 2016. histórico. XVI Encontro da Compós, Curitiba, v. 16, 2007.

LIMA, J. C. Uma história da TV Cultura. São Paulo: Imprensa Oficial do Estado de São Paulo: Cultura, Fundação Padre Anchieta, 2008.

LOPES, I. S. TV Brasil e a construção da Rede Naciona de Televisão Pública. Jundiaí: Paco Editorial, 2015.

MAZZIOTI, Nora. Os gêneros televisivos na televisão pública. In: Rincón, Omar (Org.). Televisão pública: do consumidor ao cidadão. São Paulo: SSRG.10, 2002

MOYSES, D. et al. Sistemas públicos de comunicação no mundo - Experiências de doze países e o caso brasileiro. São Paulo: Paulus/Intervozes, 2009.

OTONDO, T. M. Televisão pública: para quem e para

PORTAL CMAIS. A bola vai rolar na TV Cultura. Porta de Conteúdo Multimídia, 2011. Disponível em: <http:// cmais.com.br/a-bola-vai-rolar-na-tv-cultura>. Acesso em: 10 fev 2016.

Português ao vivo. Portal Uol, 2006. Disponível em: <http://noticias.uol.com.br/ultnot/lusa/2006/09/05/ ult3841u286.jhtm>. Acesso em: 10 fev 2016.
LEAL FILHO, L. A televisão pública brasileira, um vazio quê? São Paulo, Annablume, 2012
ROCHA, L. V. A televisão pública num ambiente de competição comercial - estudo dos modelos português e brasileiro. Tese de Doutorado. São Paulo: ECA/USP, 2006.

SANTOS, Anderson. D. G. O dilema da TV Brasil para a Série C em 2014. Observatório da Imprensa, 2013. Disponível em: <http://observatoriodaimprensa. com.br/tv-emquestao/_ed772_o_dilema_da_tv_ brasil_para_a_serie_c_em_2014>. Acesso em 25 jan 2016.

SAVENHAGO, I. J. Futebol na TV: evolução tecnológica e linguagem de espetáculo. Verso e Reverso, v. 25, n. 58, p. 22-31, 2011. https:/doi.org/10.4013/ver.2011.25.58.03.

TOSTA, A.; COUTINHO, I. Telejornalismo esportivo na TV Brasil: os programas No Mundo da Bola e Stadium. In: COUTINHO, lluska (org). A informação na TV Pública. Florianópolis: Insular, 2013.

VALENTE, J. TV pública no Brasil: a criação da TV Brasil e sua inserção no modo de regulação setorial da televisão brasileira. Dissertação de Mestrado. Brasília: Universidade de Brasília (UnB), 2009.

\section{Notas}

1 Pós-doutorado em Ciências da Comunicação pela Escola de Comunicações e Artes da Universidade de São Paulo (ECA/USP). Doutor em Comunicação e Semiótica pela PUC/SP e Professor da Escola de Educação Física e Esporte da Universidade de São Paulo (EEFE/USP). (Av. Professor Mello de Morais, 65, São Paulo-SP, CEP: 05508-030). E-mail: aryrocco@usp.br. 
2 Mestranda no curso de Mestrado Profissional em Administração: Gestão do Esporte (MPA-GE) da Universidade Nove de Julho (Uninove - Av. Francisco Matarazzo, 612, São Paulo-SP, CEP: 05001-000). E-mail: priscilacestari@yahoo.com.br.

3 Decreto publicado em 02 de setembro de 2016 no Diário Oficial da União (DOU) alterou o Estatuto Social da Empresa Brasil de Comunicação (EBC). De acordo com o texto, a empresa passou a ser vinculada à Casa Civil e não mais à Secretaria de Comunicação Social da Presidência da República. Além disso, a Medida Provisória também publicada no DOU definiu que a empresa seja administrada por um Conselho de Administração e por uma Diretoria Executiva e, em sua composição, conte com um Conselho Fiscal e não mais com um Conselho Curador. A lei que criou a empresa previa a atuação de um Conselho Curador, formado por 22 membros, incluindo representantes da sociedade civil. Disponível em: $\quad<$ http://pesquisa.in.gov.br/imprensa/jsp/visualiza/index.jsp?jornal=1\&pagina $=6 \&$ data $=02 / 09 / 2016>$. Acesso em: 11 nov 2016. 